DOI: $10.5800 / G T-2021-12-3-0545$

\title{
REPLY TO COMMENTS FROM S.G. SKUBLOV, A.V. BEREZIN, AND L.I. SALIMGARAEVA ON THE ARTICLE AUTHORED BY M.V. MINTS AND K.A. DOKUKINA - THE BELOMORIAN ECLOGITE PROVINCE (EASTERN FENNOSCANDIAN SHIELD, RUSSIA): MESO-NEOARCHEAN OR LATE PALEOPROTEROZOIC?
}

\author{
M.V. Mints ${ }^{凶}$, K.A. Dokukina ${ }^{\circledR}$
}

Geological Institute, Russian Academy of Sciences, 7 Pyzhevsky Ln, Moscow 119017, Russia

ABSTRACT. In their research, the authors of the comments have focused on the Late Paleoproterozoic rims of zircons, but ignored many important details of their own data. Their comments are based on a misconception that eclogite zircons have unique geochemical (REE, Th/U) and isotopic ( $\mathrm{Lu}-\mathrm{Hf}, \delta^{18} \mathrm{O}$ ) characteristics that do not depend on rock types and pressure rates (that were high or ultrahigh) during metamorphism. This idea leads to false unambiguous dating of the eclogite facies metamorphism based on single samples of the rocks.

FOR CITATION: Mints M.V., Dokukina K.A., 2021. Reply to comments from S.G. Skublov, A.V. Berezin, and L.I. Salimgaraeva on the article authored by M.V. Mints and K.A. Dokukina - The Belomorian eclogite province (Eastern Fennoscandian shield, Russia): MesoNeoarchean or Late Paleoproterozoic? Geodynamics \& Tectonophysics 12 (3), 662-667. doi:10.5800/GT-2021-12-3-0545 


\title{
ОТВЕТ НА КОММЕНТАРИИ К СТАТЬЕ М.В. МИНЦА И К.А. ДОКУКИНОЙ «СУБДУКЦИОННЫЕ ЭКЛОГИТЫ БЕЛОМОРСКОЙ ЭКЛОГИТОВОЙ ПРОВИНЦИИ (ВОСТОК ФЕННОСКАНДИНАВСКОГО ЩИТА, РОССИЯ): МЕЗОАРХЕЙ, НЕОАРХЕЙ ИЛИ ПОЗДНИЙ ПАЛЕОПРОТЕРОЗОЙ?» (С.Г. СКУБЛОВ, А.В. БЕРЕЗИН, Л.И. САЛИМГАРАЕВА)
}

\author{
М.В. Минц, К.А. Докукина
}

\author{
Геологический институт РАН, 119017, Москва, Пыжевский пер., 7, Россия
}

\begin{abstract}
АНнотАция. Авторы Комментариев, определив в качестве главного объекта своего исследования позднепалеопротерозойские каймы цирконов, проигнорировали многие важные детали ими же полученных данных. Комментарии базируются на ложной идее, будто бы эклогитовые цирконы обладают уникальными геохимическими (REE, Th/U) и изотопными (Lu-Hf, $\left.\delta^{18} \mathrm{O}\right)$ характеристиками, которые не зависят от типа породы и высокого или сверхвысокого давления при метаморфизме, что позволяет однозначно датировать эклогитовый метаморфизм по единичным образцам.
\end{abstract}

\section{1. ВВЕДЕНИЕ}

Комментарии посвящены тем разделам нашей работы, в которых рассматриваются изотопно-геохронологические и геохимические особенности состава циркона из эклогитов, а также особенности микровключений в минералах эклогитов. Все прочие важные направления нашего исследования - геологическое строение и геодинамические обстановки в истории Беломорской эклогитовой провинции (БЭП), разнообразие составов протолитов эклогитов ассоциации Салма (AC), различные морфология, геохимия и история кристаллизации и перекристаллизации цирконов из эклогитов-метагаббро, гранатитов и эклогитов-метагаббро-норитов, обсуждение особенностей современной океанской коры в качестве образа протолита эклогитовой ассоциации Салмы, сопоставление особенностей цирконов и минеральных включений в цирконах и гранатах AC с особенностями фанерозойских эклогитов и другие направления, представленные и детально проиллюстрированные в нашей статье, - в Комментариях не упоминаются. Для ответа на все замечания, возражения и критику, представленные в Комментариях, пришлось бы переписать целые разделы нашей статьи. Учитывая ограниченность размера публикации, мы рассмотрим только наиболее существенные замечания.

Уже на ранней стадии исследования БЭП С.Г. Скублов с соавторами приняли в качестве методического базиса постулат: «Установленные закономерности распределения редких и редкоземельных элементов в цирконах из эклогитов универсальны, они не зависят от типа породы (метабазиты, метаультрабазиты, гнейсы) и величины давления (эклогиты высокого и сверхвысокого давления). Комплексное использование этих признаков позволяет уверенно отличать эклогитовые цирконы от цирконов магматического генезиса и метаморфических цирконов, не связанных с высокобарическим метаморфизмом» [Skublov et al., 2012, p. 470]. Близкие по смыслу постулаты были приняты в отношении Lu-Hf изотопной системы [Herwartz et al., 2012] и параметра $\delta^{18} 0$ [Skublov et al., 2018]. Эти постулаты образовали методическую основу реконструкции возраста эклогитового метаморфизма, опирающуюся на анализ единичных образцов, более или менее случайно отобранных на обнажениях Салмы без учета особенностей протолитов эклогитов.

Ошибочность первого постулата продемонстрирована нами на с. 193 и рис. 37 (также в статье [Mints, Dokukina, 2020b], p. 29, Fig. 32): работоспособность «эталона эклогитового циркона» проиллюстрирована сопоставлением трендов REE в позднепалеопротерозойских каймах цирконов из эклогитов БЭП с расчетным «эталоном» [Skublov et al., 2012, Fig. 15]. Копия этой диаграммы на рис. 37 показывает, что семь трендов REE из 21, характеризующих цирконы БЭП (каждый третий!), оказались за пределами 95\%-ного квантиля, что кардинально противоречит гипотезе о принадлежности поздних кайм цирконов из эклогитов БЭП «эталону эклогитового циркона». Авторы Комментариев (далее АК) предпочли обойти молчанием эту часть нашей статьи.

Раздел «Нf-изотопная система» АК неожиданно начинают с утверждения, «что Lu-Hf (метода) датирования циркона, на который ссылаются авторы комментируемой статьи, нет. Есть исследование изотопной системы Нf в цирконах ... (т.н. Нf-систематика)». Странное утверждение, с учетом научной специализации АК. B Encyclopedia of Scientific Dating Methods статья «Lu-Hf Dating: The Lu-Hf Isotope System» включает специальный раздел «The Lu-Hf Isochron Method» [Vervoort, 2014]. Программы ведущих вузов России, в частности МГУ, включают соответствующие разделы и задания [Kostitsyn, 2019].

Возвращаясь к критике нашей статьи, цитируем АК: «...практически неизменное с отметки возраста около 2.9 млрд лет ${ }^{176} \mathrm{Hf} /{ }^{177} \mathrm{Hf}$ отношение демонстрирует всплеск на отметке U-Pb возраста около 1.9 млрд лет. Интерпретация следующая (в подписи к рис. 34, a): «Около 1.9 млрд лет зафиксирована «мгновенная» добавка в цирконе радиогенного ${ }^{176} \mathrm{Hf}$, который мог высвободиться только в результате перекристаллизации длительное время существовавшего архейского граната». Эта фраза очень хорошо характеризует стиль 
авторов «смешивать» очевидный факт (рост в цирконе радиогенного ${ }^{176} \mathrm{Hf}$ ) с ими не доказанными (возраст граната и его потенциальный вклад в бюджет Hf в цирконе). Где же доказательства, что возраст граната архейский? Какими изотопными методами датирования граната пользовались авторы [Mints, Dokukina, 2020a], чтобы так уверенно говорить о его возрасте?», далее еще пять вопросов близкой направленности.

Странным образом АК ограничились просмотром рис. 34, а, и подписи к нему. Между тем обстоятельному рассмотрению этой проблемы посвящен раздел 6.8 нашей статьи на с. 187-189, рис. 32, 33 и 34. Здесь мы ограничимся обсуждением ответов, которые предлагают АК на поставленные ими же вопросы, цитируем: «Если рассматривать каймы циркона как частично перекристаллизованные ядра, то при этом процессе было привнесено не менее 4000 ppm Hf, что в 40000 раз (!) превышает его содержание в гранате. Эта оценка увеличится более чем вдвое, если считать каймы циркона новообразованными, без перекристаллизации ядер. Гипотетически перекристаллизация даже всего существующего в породе граната не в состоянии обеспечить такой скачок содержания гафния во флюиде. ... В цирконе палеопротерозойского возраста с общим содержанием $\mathrm{Hf}$ около $9000 \mathrm{ppm}$ и ${ }^{176} \mathrm{Hf} /{ }^{177} \mathrm{Hf}$ отношением около 0.282 содержание ${ }^{176} \mathrm{Hf}$ оценивается уже как 470 ppm. Прирост радиогенного изотопа ${ }^{176} \mathrm{Hf}$, даже с учетом всех возможных погрешностей, не меньше 200 ppm. Это количество в $10^{6}$ (!) раз больше, чем мог бы обеспечить гранат».

Ключевые моменты математических выкладок выделены в Комментариях восклицательными знаками. Именно этими знаками обозначена кардинальная ошибка в расчетах. Расчет геохимических балансов должен включать количества участвующих в реакции минералов. Обогащение изотопом ${ }^{176} \mathrm{Hf}$ отмечено в цирконах из гранатитов (до 90 \% граната), подвергшихся, равно как и все породы АС, высокотемпературному метаморфизму 1.9 млрд лет назад. В нашей статье на c. 170-171 показано, что каймы цирконов из гранатитов - это перекристаллизованные области первичного циркона. Ориентировочно содержание циркона в гранатите может достигать нескольких г/т. Соответственно, в противовес утверждениям, помеченным восклицательными знаками, количество ${ }^{176} \mathrm{Hf}$, сброшенного при рекристаллизации граната, содержание которого в породе в 0.2-1.0×106 превышает содержание циркона, вполне достаточно даже для максимальных и тем более промежуточных значений ${ }^{176} \mathrm{Hf} /{ }^{177} \mathrm{Hf}$ на рис. 34 , а. Типичность обнаруженной нами закономерности подтверждают аналогичные данные для эклогитов по метагаббро-норитам (рис. 34, б, по данным из [Yu et al., 2017]).

АК ищут поддержки своим выводам в статье [O’Reilly et al., 2008]. В своем пересказе они принципиально искажают содержание этой статьи: распределение ${ }^{176} \mathrm{Hf} /{ }^{177} \mathrm{Hf}$ в цирконе из гранатита, датированном 1.9 млрд лет, в статье O’Reilly et al. вообще не рассматривается, в том числе на рис. 3 (с. 986), на который ссылаются АК. Обсуждение O'Reilly et al. адресовано двум другим образцам: эклогиту-метагаббро-нориту, метаморфизованному в гранулитовой фации 2.7 млрд лет назад, и эклогитуметагаббро, где последовательность оценок возраста охватывает интервал от 2.8 до 1.9 млрд лет.

Заметим также, что задача раздела 6.8 нашей статьи состояла не в обосновании «архейского возраста», а в рассмотрении свидетельств высокотемпературной перекристаллизации эклогитов Салмы 1.9 млрд лет назад. Приведенное выше обсуждение позволяет считать лишенным основания негативный вывод АК: «...данные об изотопном составе Hf в цирконе опровергают предположения авторов [Mints, Dokukina, 2020a] об архейском возрасте эклогитового метаморфизма, никак не подкрепленные прямыми изотопно-геохимическими и геохронологическими определениями». Следующий вывод «Устойчивость же Lu-Hf системы (в гранате) подвергается сомнению из-за «неясной» температуры закрытия системы в гранате [Mints et al., 2014; Mints, Dokukina, 2020a]» предлагает ложную трактовку комплексного обсуждения проблемы, которое представлено в разделе 6.8 нашей статьи (с. 37 и далее) и, конечно же, не ограничивается рис. 34 , a [Mints, Dokukina, 2020a].

\section{2. ИЗОТОПНАЯ СИСТЕМА КИСЛОРОДА}

АК: «Современными исследованиями установлено, что для циркона и граната значение $\delta^{18} 0$ является одним из самых надежных критериев, отражающих условия их генезиса ... [Page et al., 2014; Rubatto, Angiboust, 2015]. ... Результаты исследования в минералах из будин эклогитов Куру-Ваары (с магматическим протолитом архейского возраста) показали, что изотопный состав кислорода в гранате $\left(\delta^{18} 0=4.0-5.0 \%\right)$ находится в равновесии с составом палеопротерозойского (около 1.9 млрд лет) циркона $\left(\delta^{18} 0=4.5-5.4 \%\right) ;$ значения же $\delta^{18} 0$ в магматических доменах циркона архейского возраста (примерно 2.88 млрд лет) значительно выше (5.1-5.9\%) и не равновесны с таковыми в гранате».

Этот пассаж некорректен от начала и до конца. (1) В разделе 6.8 мы показали, что 1.9 млрд лет - это возраст перекристаллизованного, а не первичного эклогитового граната. (2) Ссылки на статьи [Page et al., 2014; Rubatto, Angiboust, 2015] принципиально искажают их содержание. В этих работах рассматривается эволюция $\delta^{18} 0$ в процессе субдукции океанской литосферы, то есть в условиях сценария, с которым С.Г. Скублов с соавторами ведут бескомпромиссную борьбу, противопоставляя ему модель «коллизионного» эклогитового метаморфизма, состоявшегося через 1 млрд лет после формирования магматического протолита. Согласно авторам статей, при средне- и низкотемпературном метаморфизме спредингового хребта и океанского дна значения $\delta^{18} 0$, соответствующие океанским габброидам (4.3-4.6 \%о [Page et al., 2014, Fig. 12] и 5 \%о [Rubatto, Angiboust, 2015, Fig. 9]), снижаются до 1-4\%. При эклогитовом метаморфизме оценки $\delta^{18} \mathrm{O}$ составили 
3.7 \%о [Page et al., 2014, Fig. 12] и 0.2-3.8 \%о [Rubatto, Angiboust, 2015, Fig. 9]. Затем $\delta^{18} 0$ значительно возрастает в результате реакций в равновесии с осадочным матриксом - до 4.3-6.4 \%о в гранате и цирконе и до 24 \%о в позднем кварце [Page et al., 2014, Fig. 12]. Именно такой тип эволюции $\delta^{18} 0$ представлен на рис. 34 , в, в нашей статье [Mints, Dokukina, 2020a]: диаграмма «U-Pb возраст $-\delta^{18} 0$ » в интервале от $\sim 2.72$ до $\sim 2.60$ млрд лет демонстрирует снижение $\delta^{18} 0$ от 6.1 до 5.7 ; затем около 1.9 млрд лет назад (спустя 0.8-0.7 млрд лет) зафиксирован значительный прирост значений $\delta^{18} 0$ до 6.2-6.8, указывающий на участие флюидов, дренирующих осадочную толщу (по данным из [Yu et al., 2017]).

В разделе «Минеральные включения в эклогитах» АК предлагают критический анализ интерпретации доэклогитовых низко- и среднетемпературных минеральных включений, а также расплавных включений в гранате, цирконе и иногда - в матриксе эклогита, которые приведены в нашей статье [Mints, Dokukina, 2020a]. АК предлагают свое видение условий образования минеральных ассоциаций и стремятся доказать постэклогитовое появление включений. В нашей статье детальное обсуждение условий кристаллизации минеральных ассоциаций, образующих включения, отсутствует, поскольку эта задача выходит далеко за рамки нашей статьи. Мы заимствовали характеристику минеральных включений из публикаций, прошедших серьезное рецензирование, и не видим основания для вступления в дискуссию о параметрах и условиях равновесия отдельных метаморфических реакций. При метаморфизме в обстановках спредингового хребта и морского дна полнокристаллические породы подвергаются гидротермальной трансформации и выветриванию, то есть воздействию водного флюида. Резкая смена температурного и водного режима связана с погружением в зону субдукции. В самом общем виде ответ на критику АК содержится в известной модели «мозаичного равновесия» [Korzhinsky, 1955].

Заметим, что цитирование фрагментов нашего текста в Комментариях, - это, как правило, весьма вольный и зачастую искажающий смысл нашего текста пересказ, который было бы странно обсуждать. Вот характерный пример. АК: «На с. 167, приводя интерпретацию магматических ядер циркона с возрастом около 2.9 млрд лет, авторы указывают на наличие включений, отвечающих параметрам пренит-пумпеллиитовой фации метаморфизма, оценивая значения температуры в $850{ }^{\circ} \mathrm{C}$. Остается неясной причина стабильности водосодержащих фаз при такой значительной температуре и крайне малой активности воды». Причина «неясности» предельно проста: абзац от начала до слова «реликтовые» размещен на с. 166, а завершение фразы (оценки температуры ...) - на с. 167. АК, читавшие нашу статью «по диагонали», не обратили внимания на специальные подробно проиллюстрированные разделы: 6.3. Возраст, минеральные и геохимические индикаторы происхождения протолитов эклогитовой ассоциации (с. 179-180) и 6.4. Метаморфизм протолитов в обстановках спредингового центра и океанского дна (с. 180-183).

\section{3. ОБОСНОВАНИЕ ВОЗРАСТА ЭКЛОГИТОВ}

АК: «Переходя собственно к обоснованию авторами статьи архейского возраста эклогитов, следует особенно отметить первую фразу авторов в этом разделе, что «собственно эклогитовые цирконы в эклогитах Салмы не были обнаружены» (с. 183). То есть эклогиты есть, а цирконов, отвечающих высокобарическому метаморфизму, полностью преобразовавшему облик протолита, в них нет (!)». В действительности, на c. 183 нашей статьи читаем: «В первоначальных публикациях, характеризующих БЭП, точные датировки и продолжительность эклогитового метаморфизма в ассоциации Салма не были представлены, поскольку собственно эклогитовые цирконы в эклогитах Салмы не были обнаружены». И далее в отношении геохимических особенностей циркона на с. 184: «... тренды REE демонстрируют появление положительной Eu-аномалии при максимальной концентрации REE. Наиболее ранний зафиксированный возраст положительной Eu-аномалии - 2.79 млрд лет. Синхронное исчезновение положительной Се-аномалии и возникновение положительной Еu-аномалии невозможно связать с изменениями окислительно-восстановительных свойств среды минералообразования [Hoskin, Schaltegger, 2003; Trail et al., 2012]. Положительная Eu-аномалия указывает на фракционирование плагиоклаза. Наиболее вероятным механизмом фракционирования является перекристаллизация мафитовой магматической породы (плагиоклаз + клинопироксен) с образованием эклогитовой ассоциации «гранат + омфацит». Пористый циркон в ходе реакций растворения - переосаждения захватывает высвобождающийся Eu. Поскольку титанит является одним из главных концентраторов LREE в метагаббро [Henderson, 1980; Marks et al., 2008], а рутил, напротив, содержит исчезающие малые концентрации REE [Zeh et al., 2018], максимальные концентрации LREE и MREE в цирконе можно объяснить реакцией замещения титанита рутилом, которая связана переходом к РТ-параметрам эклогитовой фации [Angiboust, Harlov, 2017; Müller et al., 2018]: высвобождаемые REE утилизируются пористым цирконом. ... Как видно на рис. 17,18 , положительная Еu-аномалия может сохраняться в трендах REE более молодых участков циркона». Аналогично в Conclusion в [Mints, Dokukina, 2020b]: «The LREE and MREE enrichment, the disappearance of the Ce positive anomaly, a change from negative to positive Eu anomaly at 2.82-2.78 Ga indicate plagioclase removal during the formation of the eclogite garnet+omphacite association and replacement of rutile with sphene. The eclogite facies metamorphism linked with subduction of the oceanic crust is also indicated by the microinclusions of garnet and rutile in zircon» (p. 34).

Отсутствие самостоятельных эклогитовых цирконов в породах Салмы не является уникальным явлением. Например, цирконы эклогитов по Fe-Ti габброидам 
комплекса Mulhacén в Бетических Кордильерах на юговостоке Испании включают домены трех типов: магматические области с осцилляторной зональностью, датирующие кристаллизацию протолита в средней юре, и два типа рекристаллизованных метаморфических доменов (поздний мел - палеоцен), один с серыми однородными CL изображениями и другой с яркими облачными CL изображениями, которые интерпретируются как производные метаморфизма океанического дна и метаморфизма в условиях эклогитовой фации соответственно [Puga et al., 2005].

\section{4. ЗАКЛЮЧЕНИЕ}

Авторы Комментариев считают геохимическое и изотопно-геохимическое исследование цирконов и гранатов единичных образцов достаточным для оценки возраста эклогитового метаморфизма. Несостоятельность этого подхода продемонстрирована в нашей статье и вызвала критику. Однако, определив в качестве главного объекта исследования позднепалеопротерозойские каймы цирконов, С.Г. Скублов и его соавторы и единомышленники проигнорировали многие важные детали полученных ими же данных [Mints, Dokukina, 2020a, с. 193]. Комментарии в значительной части базируются на прочтении «по диагонали» нашей статьи, равно как и статей авторитетных авторов, на которые АК хотели бы опереться.

\section{5. ЛИТЕРАТУРА / REFERENCES}

Angiboust S., Harlov D.E., 2017. Ilmenite Breakdown and Rutile-Titanite Stability in Metagranitoids: Natural Observations and Experimental Results. American Mineralogist 102 (8), 1696-1708. https://doi.org/10.2138/am-20 17-6064.

Henderson P., 1980. Rare Earth Element Partition between Sphene, Apatite and Other Coexisting Minerals of the Kangerdlugssuaq Intrusion, E. Greenland. Contributions to Mineralogy and Petrology 72 (1), 81-85. https://doi.org/ 10.1007/BF00375570.

Herwartz D., Skublov S.G., Berezin A.V., Mel'nik A.E., 2012. First Lu-Hf Garnet Ages of Eclogites from the Belomorian Mobile Belt (Baltic Shield, Russia). Doklady Earth Sciences 443 (1), 377-380. https://doi.org/10.1134/S1028334X1 2030130.

Hoskin P.W.O., Schaltegger U., 2003. The Composition of Zircon and Igneous and Metamorphic Petrogenesis. Reviews in Mineralogy and Geochemistry 53, 27-62. https:// doi.org/10.2113/0530027.

Korzhinsky D.S., 1955. Essay on Metasomatic Processes. In: A.G. Betekhtin (Ed.), Basic Problems in Studies of Magmatogenic Ore Deposits. Publishing House of the USSR Academy of Science, p. 335-456 (in Russian) [Коржинский Д.C. Очерк метасоматических процессов // Основные проблемы в учении о магматогенных рудных месторождениях / Ред. А.Г. Бетехтин. М.: Изд-во АН СССР, 1955. C. 335-456].

Kostitsyn Yu.A., 2019. Work Program of the Discipline "Geochemistry of Isotopes and Geochronology". Faculty of
Geology, MSU, Moscow, 12 p. (in Russian) [Костицын Ю.А. Рабочая программа дисциплины «Геохимия изотопов и геохронология». М.: Геологический факультет МГУ им. М.В. Ломоносова, 2019. 12 с.].

Marks M.A.W., Coulson I.M., Schilling J., Jacob D.E., Schmitt A.K., Markl G., 2008. The Effect of Titanite and Other HFSE-Rich Mineral (Ti-Bearing Andradite, Zircon, Eudialyte) Fractionation on the Geochemical Evolution of Silicate Melts. Chemical Geology 257 (1-2), 153-172. https://doi. org/10.1016/j.chemgeo.2008.09.002.

Mints M.V., Dokukina K.A., 2020a. The Belomorian Eclogite Province (Eastern Fennoscandian Shield, Russia): Meso-Neoarchean or Late Paleoproterozoic? Geodynamics \& Tectonophysics 11 (1), 151-200 (in Russian) [Минц М.В., Докукина К.А. Субдукционные эклогиты Беломорской эклогитовой провинции (восток Фенноскандинавского щита, Россия): мезоархей, неоархей или поздний палеопротерозой? // Геодинамика и тектонофизика. 2020. T. 11. № 1. C. 151-200]. https://doi.org/10.5800/GT-202011-1-0469.

Mints M.V., Dokukina K.A., 2020b. Age of Eclogites Formed by the Subduction of the Mesoarchaean Oceanic Crust (Salma, Belomorian Eclogite Province, Kola Peninsula, Russia): A Synthesis. Precambrian Research 350, 105879. https://doi.org/ 10.1016/j.precamres.2020.105879.

Mints M.V., Dokukina K.A., Konilov A.N., 2014. The MesoNeoarchaean Belomorian Eclogite Province: Tectonic Position and Geodynamic Evolution. Gondwana Research 25 (2), 561-584. https://doi.org/10.1016/j.gr.2012.11.010.

Müller S., Dziggel A., Kolb J., Sindern S., 2018. Mineral Textural Evolution and PT-Path of Relict Eclogite-Facies Rocks in the Paleoproterozoic Nagssugtoqidian Orogen, South-East Greenland. Lithos 296-299, 212-232. https:// doi.org/10.1016/j.lithos.2017.11.008.

O’Reilly S.Y., Griffin W.L., Pearson N.J., Jackson S.E., Belousova E.A., Alard O., Saeed A., 2008. Taking the Pulse of the Earth: Linking Crustal and Mantle Events. Australian Journal of Earth Sciences 55 (6-7), 983-995. https://doi. org/10.1080/08120090802097450.

Page F.Z., Essene E.J., Mukasa S.B., Valley J.W., 2014. A Garnet-Zircon Oxygen Isotope Record of Subduction and Exhumation Fluids from the Franciscan Complex, California. Journal of Petrology 55 (1), 103-131. https://doi.org/10. 1093/petrology/egt062.

Puga E., Fanning C.M., Nieto J.M., De Federico A.D., 2005. Recrystallization Textures in Zircon Generated by OceanFloor and Eclogite-Facies Metamorphism: A Cathodoluminescence and U-Pb Shrimp Study, with Constraints from REE Elements. The Canadian Mineralogist 43 (1), 183-202. https://doi.org/10.2113/gscanmin.43.1.183.

Rubatto D., Angiboust S., 2015. Oxygen Isotope Record of Oceanic and High-Pressure Metasomatism: A P-T-TimeFluid Path for the Monviso Eclogites (Italy). Contributions to Mineralogy and Petrology 170 (44), 1-16. https://doi. org/10.1007/s00410-015-1198-4.

Skublov S.G., Berezin A.V., Berezhnaya N.G., 2012. General Relations in the Trace-Element Composition of Zircons from Eclogites with Implications for the Age of Eclogites in the 
Belomorian Mobile Belt. Petrology 20 (5), 427-449. https:// doi.org/10.1134/S0869591112050062.

Skublov S.G., Berezin A.V., Mel'nik A.E., Lee S.-Kh., Rubatto D., Herwartz D., 2018. Paleoproterozoic Eclogites of the Belomorian Belt: Data of Radiogenic and Stable Isotopes for Rock-Forming and Accessory Minerals. In: Along the Wake of a Large Ship: Current Problems of Magmatism, Metamorphism and Geodynamics. Proceedings of the III Conference Dedicated to the 85th Anniversary of the Honored Professor of Moscow State University L.L. Perchuk (November 23-24, 2018). Chernogolovka, p. 67-68 (in Russian) [Скублов С.Г., Березин А.В., Мельник А.Е., Ли С.Х., Рубатто Д., Хервартц Д. Палеопротерозойские эклогиты Беломорского пояса: данные радиогенных и стабильных изотопов для породообразующих и акцессорных минералов // В кильватере большого корабля: современные проблемы магматизма, метаморфизма и геодинамики: Материалы III конференции, посвященной 85-летию со дня рождения заслуженного профессора
МГУ Л.Л. Перчука (23-24 ноября 2018 г.). Черноголовка, 2018. С. 67-68].

Trail D., Watson E.B., Tailby N.B., 2012. Ce and Eu Anomalies in Zircon as Proxies for the Oxidation State of Magmas. Geochimica et Cosmochimica Acta 97 (15), 70-87. https:// doi.org/10.1016/j.gca.2012.08.032.

Vervoort J., 2014. Lu-Hf Dating: The Lu-Hf Isotope System. In: W. Rink, J. Thompson (Eds), Encyclopedia of Scientific Dating Methods. Springer, Dordrecht. https://doi. org/10.1007/978-94-007-6326-5_46-1.

Yu H.L., Zhang L.F., Wei C.J., Li X.L., Guo J.H., 2017. Age and P-T Conditions of the Gridino-Type Eclogite in the Belomorian Province, Russia. Journal of Metamorphic Geology 35, 855-869. https://doi.org/10.1111/jmg.12258.

Zeh A., Cabral A.R., Koglin N., Decker M., 2018. Rutile Alteration and Authigenic Growth in Metasandstones of the Moeda Formation, Minas Gerais, Brazil - A Result of Transamazonian Fluid-Rock Interaction. Chemical Geology 483, 397-409. https://doi.org/10.1016/j.chemgeo.2018.03.007. 